\title{
Assessing the Effectiveness of Computer Assisted Instructions in Physics at Undergraduate Level
}

\author{
Popat Savaleram Tambade ${ }^{1, *}$ and Bhiva Gobji Wagh ${ }^{2}$ \\ ${ }^{1}$ Prof. Ramkrishna More College, Akurdi, Pune, India \\ ${ }^{2}$ K.K.Wagh Arts, Commerce and Science College, Pimpalgaon (B), Nashik, India
}

Received: 28 March 2011 - Revised: 23 June 2011 - Accepted: 04 July 2011

\begin{abstract}
Previous researchers have demonstrated significant improvement in students' conceptual understanding of basic physics using interactive engagement methods of instruction. In this study, the effects of interactive computerbased simulations and animations investigated in classroom on students' conceptual understanding of electrostatics. Two groups - one control and one experimental of students at third year undergraduate level were studied to determine the role of computer simulations and animations in the development of functional understanding of the concepts of force, field, and potential in electrostatics. While few misconceptions persisted, the overall results indicate that students seem to have acquired a good general understanding of these concepts using such package. This occurred mainly in the area of verbal, vector and diagrammatic representation of the abstract physics concepts involved in the study.
\end{abstract}

Keywords: Computer Simulation, Physics Education, Electrostatics, Computer-Assisted Instructions.

\section{Introduction}

In recent years, a number of factors have prompted change in the teaching of physics, particularly at upper secondary and undergraduate levels. Changes have been made in the development of courses and curricula and in the teaching methods. This has been happening across the world. Changes to courses, curricula and instructional methods, or in some cases, the contemplation of changes, have been driven by concerns about traditional teaching methods (that they are not the most appropriate for teaching physics to all students and do not make the best use of advanced technologies, for example) and a decline in the number of students choosing physics as a major field of study (McDermott, 2001; Meltzer, 2005; Maloney et. al., 2001, Pollock, 2009, McBridge, Zollaman \& Rebello, 2010).

Advancing technology has opened many doors in physics education. The use of computer based teaching in physics provides number of alternatives to students such as visualization of abstract concepts that will foster student understanding (Meltzer \& Manivannan, 2002). These alternatives would be complementary to traditional teaching. Computer assisted instructional materials are more effective in developing favorable attitude, and in capturing interest towards learning physics (Azar \& Şengüleç, 2011). The activities that aid student the visualization of abstract concepts will foster their conceptual understanding. These activities would be complementary to traditional teaching, and could be

\footnotetext{
*Corresponding Author: Phone: +91 20 66302104, Fax: +91 20 27659740, Email: pstam3@rediffmail.com
} ISSN: 1306-3049, (C2011 
concrete physical activities, or computer simulations and animations (Fraser et. al., 2007; Bayrak, 2008; Serin, 2011). Computer simulations seem to be one of the most effective ways to use computers in physics education. The computer simulations prepared to be used in teaching activities are able to create a teaching atmosphere like laboratories where students are active (Perkins et. al., 2006). A variety of visual representations of physics concepts in the computer simulations make concepts visible that are otherwise invisible to students (Finkelstein et. al., 2005). They encourage students to carry out the processes used in physics research: to question, predict, hypothesize, observe, interpret results etc. and also motivates and cultivates students' interest in learning physics, and can heighten the individualized instruction by allowing students to proceed on their own pace and are able to go back to master the skills (Holec, Spodniaková Pfefferová.\& Raganová, 2004; Ubiña \& Patricio, 2007). Various interference possibilities exist in simulation programs. The user giving different initial values in the experiment in computer medium and observing the effect gives the possibility of "Learning through inventing" (Bayrak, Kanlı \& Kandil İngeç, 2007; Keller et. al., 2007; Monaghan, 1998). Simulations offer instructors the opportunity to provide students with an instructional tool that can help students transform their alternative science conceptions into correct science conceptions. Students could isolate and manipulate parameters and therefore help them to develop an understanding of the relationships among physical concepts, variables and phenomena (Tao \& Gunstone, 1999; Arvind \& Heard, 2010; Bakaç, Taşoglu \& Akbay, 2011). Computer animations offer the potential for increased learning when there is a need for external visualization and when the content depends on an understanding of motion (Dancy \& Beichner, 2006).

The present study aims to investigate whether computer assisted instruction is more effective than traditional instruction in increasing student success in physics at undergraduate level. The topic of "Electrostatics" was selected for instructions since it is hard to understand due to the abstract nature of the quantities such as electric field, flux, and potential (Chabay \& Sherwood, 2006). The correct understanding of electrostatic phenomena and principles are essential for students in their future learning such as electromagnetic field theory, optics, electronics, and various courses of technology (Saarelainen \& Hirvonen, 2009).

It has been observed that students have difficulty to visualize the electrostatic fields and also they have difficulty in interpretation of related vector representations and mathematical relationships (Bilal \& Erol, 2009). They have also problem in visualizing the movement and the direction of an electric charge in an electrical field (Bonham, Risley \& Christian, 1999). By providing animations and simulations through computer assisted instructions (CAI) to students, it was aimed to help better understand the electrical processes without entirely depending on the mathematical definitions (Gönen, Kocakaya \& İnan, 2006). The visual observation of the physical processes on computers will help the students to consolidate the knowledge gained and finds ways to link this to their real world situations. The computer environments provide students a platform to apply their knowledge in a given situation which will result in the discovery of new knowledge (Kocakaya \& Gönen, 2010). For this purpose Interactive Electrostatics Simulation Package (IESP) is developed. This package provides animations and simulations on electrostatics.

\section{Research Objectives}

Objectives of this study was to develop and evaluate an interactive computer based animation and simulation package on Electrostatics and to provide third year undergraduate students of University of Pune with an interactive means of self-learning and evaluation of this topic. 


\section{Research Questions}

To identify students' conceptual understanding in electrostatics before and after the use of computer assisted instructions following research questions were set for the study:

1) Will students be able to interpret verbal representations in electrostatics?

2) Will students be able to interpret vector representations in electrostatics?

3) Will students be able to interpret diagrammatic representations in electrostatics?

4) Will students be able to form consistent conceptual understanding in electrostatics?

\section{Methodology}

\section{Subjects}

The subjects of this study were third year undergraduate students (aged 18 to 20) from three different colleges affiliated to Pune University in the academic years 2006-07 and 200708. The students were randomly selected for two groups, control group $(\mathrm{N}=53)$, experimental group $(\mathrm{N}=53)$. A t-test was administered to find out the significance of the difference between the mean scores of the experimental and control groups.

\section{Tools}

Investigators selected a topic of Electrostatics from the course 'Classical Electrodynamics' at third year undergraduate physics. Conceptual understanding of this topic is necessary for students to study advanced topics of Classical Electrodynamics. For data collection, Electrostatic Concept Diagnostic Test (ECDT) was developed which is composed of 15 multiple choice questions mostly of qualitative nature. This test was administered for the subjects. The items in the ECDT were selected from 30 items designed by authors following expert's advice on the basis of level of difficulty and the indexes of defined differences. The ECDT covered the instructional objectives for the unit of electrostatics. There is need to identify specific difficulties students have with various representations. For this purpose, two similar items related to electrostatics were given in different representational forms. Students had to choose correct alternative for each item as well as give justification for the same. The reliability constant of the test has been determined according to KuderRichardson (KR-20) method and has been identified as 0.704 .

\section{Treatment}

The study was carried out in two phases. In the first phase, the traditional instruction was conducted over 7 lecture hours. The ECDT was administered as a pretest to 125 students at the end of traditional instruction. Students' difficulties were identified in the pretests on the basis of responses and justifications. The average difficulty index and average discrimination index of the test are 0.42 and 0.32 respectively. The instrument is moderately difficult and good discriminator.

After the pretest students were divided into experimental group and control group on the basis of random selection. During the experiments any data related to students who did not attend all activities, has been excluded from further analysis. As a result only data of 106 students' have been included in the analysis with 53 students in experimental group and 53 students in control group.

In second phase, instructors used traditional method for revision of topics for control group. The topics were revised in three lecture hours. During the revision instructors also solved some additional problems which included some conceptual and qualitative problems. In experimental group, cooperative group learning method was used. The topics were revised 
for three lecture hours using the IESP package and blackboard. After revision, 18 subgroups, each of three students, were formed. One computer for each subgroup was provided and allowed to operate the package for three hours. Worksheets were provided to students and asked to prepare answers for the questions provided in the worksheet. Necessary details have been explained with question-answer method and animations by the instructor. The students were given step by step instruction on how to use the package and asked to explore different parts of simulations embedded in it. In addition, they were assisted by instructor when they had any difficulties.

After the instruction, the same version of the ECDT, called posttest, was administered to students of experimental and control group.

Average normalized gain was used to investigate the effect of IESP approach on students' achievement on conceptual understanding about electrostatics. The normalized gain ' $\mathrm{g}$ ' for each student was obtained using the equation given by Hake (1998) as:

$$
g=\frac{\text { Posttest score-pretest score }}{100 \text {-pretestscore }}
$$

Class average normalized gain $<\mathrm{g}>$ with standard deviation was obtained for experimental group and control group. According to Hake (1998), the treatment given to be interactive, if $<\mathrm{g}>$ is greater than 0.3 . To determine whether there is any significant difference between experimental and control group, the average normalized gains have been subjected to t-test analysis.

\section{Interactive Electrostatics Simulation Package (IESP)}

The Interactive simulation package applied in experimental group has been prepared with the help of Microsoft PowerPoint ${ }^{\circledR}$, pictures and simulation using $\mathrm{C}$ programming. The content of the Electrostatics have been organized in the presentation which is in the form of six modules viz. Coulomb's law, Superposition Principle, Electric field, Electric potential, Gauss law, and Electric Dipole. The text content in the PowerPoint slides is static as well as dynamic. Cognitive enhancement was maintained by using animations to figures and vector representations to teach concepts that were inaccessible through the textbook due to the lack of the textbook's ability to show motion. Forward and backward button facilities have been used in each slide. Simulations have been hyperlinked at appropriate positions in each module. Multiple choice questions and quizzes have been added at the end of each module. The multiple choice questions are different than that used in ECDT. In simulations, students have the opportunity to observe the change in the force between two charges with variation of separation, resultant force for group of charges, magnitude and direction of electric intensity at the requested point in the field of point charges. It has been aimed to make sure that students develop their conceptual understanding by observing these changes.

The most important features of the package are:

1. This package is designed to strongly promote student-student as well as studentteacher interactions in the classroom.

2. Each simulation is designed in such way that every aspect of the phenomenon can be studied.

3. The package consists of phenomena in verbal as well as vector or diagrammatic representations. 
The package was shown to 10 physics teachers who are teaching electrostatics and their feedback was obtained. Necessary revisions were made in the package.

\section{Results}

Primary means of assessment of student learning by investigators is through comparison of student performance on post-tests and corresponding pretests.

Based on the data obtained by ECDT, the students' mean and standard deviation for pre and posttest scores for two groups were obtained. The pretest scores are presented in Table 1.

The independent sample t-test was used to determine whether there was a statistically significant mean difference between two groups for the pretest at 0.01 levels. Effect Size $(d=0.021)$ and critical significance level $p>0.01$ values indicate that there is no significance difference between mean scores in the pre-test. This result indicates that the subjects in two groups that have participated in the research are equal in terms of knowledge according to their t-test results.

Table 1. Comparison of Pretest scores with independent sample t-test

\begin{tabular}{|c|c|c|c|c|c|c|}
\hline Group & $\mathrm{N}$ & Mean Score & $\begin{array}{c}\text { Standard } \\
\text { Deviation }\end{array}$ & $\begin{array}{c}\mathrm{t} \\
(0.01)\end{array}$ & $\mathrm{p}$ & d \\
\hline Control & 53 & 36.43 & 13.74 & \multirow{2}{*}{0.1045} & \multirow{2}{*}{0.458} & \multirow{2}{*}{0.021} \\
\hline Experimental & 53 & 36.17 & 11.78 & & & \\
\hline$\left[\mathrm{t}_{\text {critical }}=2.36\right.$ & 1 & $\mathrm{df}=104]$ & & & & \\
\hline
\end{tabular}

The items in the diagnostic tests were grouped according to research questions in the study. The analysis of research question 1 showed that only $40.73 \%$ students were able to interpret verbal representations. The analysis of the research question 2 showed that only $37.12 \%$ students were able to interpret vector representations in electrostatics. The analysis of research question 3 showed that only $44.58 \%$ students were able to interpret diagrammatic representations in electrostatics. The analysis of research question 4 showed that $33.3 \%$ students were consistency in conceptual understanding. It is observed that only $29.29 \%$ students gave proper response to item on Coulomb's law in verbal form and $37.29 \%$ students gave correct response to item on Coulomb's law in vector representation. But it is observed that only $19.45 \%$ students gave the correct response on both the items simultaneously.

Table 2 shows post-test and $<\mathrm{g}>$ results of experimental group and control group.

Table 2. Post-test findings of control and experimental groups

\begin{tabular}{lccccc}
\hline Group & $\mathrm{N}$ & $\begin{array}{l}\text { Mean } \\
\text { Score }\end{array}$ & Standard Deviation & $<\mathrm{g}>$ & $\mathrm{S}$ \\
\hline Control & 53 & 50.87 & 11.78 & 0.237 & 0.148 \\
Experimental & 53 & 73.20 & 15.58 & 0.584 & 0.199 \\
\hline
\end{tabular}

( $\mathrm{S}=$ standard deviation for normalized gain for $\mathrm{g}$ ) 
Table 3. t-test analysis of normalized gains of control and experimental groups

\begin{tabular}{lcccccc}
\hline Group & $\mathrm{N}$ & $<\mathrm{g}>$ & $\mathrm{S}$ & $\begin{array}{c}\mathrm{t}-\text { value } \\
(0.01)\end{array}$ & $p$ & $d$ \\
\hline Control & 53 & 0.237 & 0.148 & 10.20 & $1.2 \times 10^{-17}$ & 1.997 \\
Experimental & 53 & 0.584 & 0.584 & & & \\
\hline
\end{tabular}

$\left[\mathrm{t}_{\text {critical }}=2.36\right.$ at 0.01 level for $\left.\mathrm{df}=104\right]$.

Table 3 shows t-test results of class average normalized gains of experimental and control groups at 0.01 significance level. Effect Size (1.997) and critical significance level $\mathrm{p}<0.01$ values indicates that there is significant difference between average normalized gains in the pre-test and post-test comparison. These results indicate that the cooperative group learning method with computer assisted instruction is more effective than passive learner computer assisted instruction method. The computer package used in cooperative group learning is more effective than used in support of traditional instruction in students' achievement in learning physics. Table 2 shows that the average normalized gain of experimental group is 2.46 times more than that of control group. Thus, the interactive computer aided instructions used for experimental group are effective in promoting conceptual understanding of electrostatics.

This research showed the result that Computer Assisted Instruction was pretty much more effective than traditional teaching in students' achievement in physics. For the analysis of research questions, the items in the test were grouped according to type of research questions. Table 4 summarizes students' performance on research questions.

Table 4. Comparison of performance on research questions

\begin{tabular}{ccc}
\hline $\begin{array}{c}\text { Research } \\
\text { Question }\end{array}$ & $\begin{array}{c}\text { Control } \\
<\mathrm{g}>\end{array}$ & $\begin{array}{c}\text { Experimental } \\
<\mathrm{g}>\end{array}$ \\
\hline 1 & 0.28 & 0.58 \\
2 & 0.18 & 0.61 \\
3 & 0.21 & 0.53 \\
4 & 0.19 & 0.52 \\
\hline
\end{tabular}

As it is shown in Table 4, the normalized gains in each research question for experimental group is more as compared to the normalized gain for control group. Since $<\mathrm{g}>$ is greater than 0.3 in each research question, the treatment used for experimental group is interactive and produces significant change in the conceptual understanding of students. The subjects in experimental group are better placed in understanding of verbal, vector, and diagrammatic representations as compared to the control group. They are also more consistent in conceptual understanding about electrostatics. It is observed that animations and simulations helped the students to understand the vector diagram and principle of superposition which may not be as observable as done inside an ordinary classroom set-up (Ubiña \& Patricio, 2007). 


\section{Discussion}

The concepts probed in diagnostic test were among the most basic concepts in electrostatics. In third year undergraduate class, students were assumed to have a good understanding of these concepts as they had studied the same topic in first year undergraduate class. The conceptual understanding of electrostatic concepts is necessary for further study in Method of electrical images, electromagnetic field theory, optics, electronics and other fields of technology. After analysis of data on the pretest scores showed that an inability to interpret equations, vector and diagrammatic representations underlies many conceptual and reasoning difficulties that students have in electrostatics (Bilal \& Erol, 2009, Saarelainen \& Hirvonen, 2009). It has been observed that most of the students were unable to relate algebraic formalism learned in electrostatics to the simple situations presented to them. The analysis of research question 2 in the present study showed that the most of the students were unable to interpret the vector representations in electrostatics. Due to this students had difficulty in understanding of superposition principle. The analysis of research question 4 showed that there were several students who gave a correct response to verbal questions, but incorrect responses to similar questions in vector or diagrammatic form. This showed that student performance on very similar physics problems posed in different representations yield strikingly different results (Chabay \& Sherwood, 2006). It was observed that most incorrect choices in pretest by students were not due to random mistakes but rather based on a stable misconception that was shared by many individuals.

The Effect Size and t-test obtained from class average normalized gains for experimental and control group in this research showed the result that Computer Assisted Instruction was much more effective than traditional teaching in students' achievement in physics (Bayrak, 2008; Yeşilyurt, 2011). Computer aided visualization of Coulomb's law using computer simulations helps students to understand the variation of force with the distance as well as the direction of forces. The simulations of electric field of point charges enabled students to understand the variation of electric intensity and potential at different points in the field as well as equi-potential surfaces. A visual representation of superposition principle is provided that allows students to study the direction and magnitude of resultant force of group of point charges that otherwise hidden to them. The simulation of electric intensity and potential of dipole allowed students to verify electric intensity and potential at any point in the field. It is observed that computer visualization of concepts from the electrostatics enhanced students' ability to transfer the concepts from the abstract level to the concrete level, thereby, improving their conceptual understanding of electrostatic phenomena (Gönen et. al., 2006; Kocakaya \& Gönen, 2010).

The analysis of research questions showed that the students in experimental group were better placed in interpretation of verbal, vector, and diagrammatic representations in electrostatics as compared to control group (Bonham et. al., 1999). It has been observed that the experimental group students are more coherent in their conceptual understanding as compared to control group students. The advantage of CAI is to allow students to concentrate on the physical meaning of the abstract concepts, hence, to get an in-depth understanding of the theory (Bayrak et. al. 2007; Azar \& Şengüleç, 2011; Hargunani, 2010).

The findings of this study shows that teaching performed with Computer Assisted Instruction is a more productive approach than the teaching performed with traditional methods. This approach is helpful in improving the student success and conceptual understanding about electrostatics. 


\section{Conclusions}

In third year undergraduate physics course it is expected that students have good understanding of basic concepts in electrostatics since they had studied these concepts in first year undergraduate level. Analysis of pretest results showed that the students have profound difficulties in understanding concepts in electrostatics. The present study showed that computer assisted instructions is an excellent way to focus students' conceptual understanding of principles in physics in general and electrostatics in particular. The results obtained in this study showed that the use of interactive teaching strategy have assisted in increasing the level of understanding of the concepts related to electrostatics. Positive intervention of Computer animations and simulations in classroom makes the real difference in student learning such as interpretation of verbal, vector and diagrammatic representations in physics. According to the results of the study, students in the experimental group substantially reduced their misconceptions in electrostatics and developed a functional understanding of physics. Through animations and simulations, it is possible for teachers to demonstrate the laws, concepts in visual form. The interactive instructions with the help of computer based instructional materials motivate and cultivate students' interest in learning physics and could indeed produce superior academic achievement.

Based on the result of this study it can be suggested that; for physics students, there is a need to determine the existing misconceptions in various topics of physics and lead those students to overcome these with the help of suitable computer assisted material. The conclusions of this study, as no doubt, have been limited by the sampling presented here. Further work would contribute to a better understanding of the subject and help to its wider applicability. Simulations, animation and multimedia packages should be developed by teachers for physics courses in order to apply CAI applications in physics classrooms.

\section{References}

Arvind, V.R. \& Heard, J.W. (2010). Physics by simulation: Teaching circular motion using applets. Latin American Journal of Physics Education, 4(1), 35-39.

Azar, A. \& Şengüleç, Ö.A. (2011). Computer-assisted and laboratory-assisted teaching methods in physics teaching: The effect on student physics achievement and attitude towards physics. Eurasian Journal of Physics and Chemistry Education, Jan (Special Issue), 43-50.

Bakaç, M., Taşoglu, A.K., \& Akbay, T. (2011). The effect of computer assisted instruction with simulation in science and physics activities on the success of student: Electric current. Eurasian Journal of Physics and Chemistry Education, Jan (Special Issue), 3242.

Bayrak, C. (2008). Effects of computer simulations programs on university students achievement in physics. Turkish Online Journal of Distance Education, 9(4), 53-62.

Bayrak, B., Kanlı, U. \& Kandil İngeç, Ş. (2007). To compare the effects of computer based learning and the laboratory based learning on students' achievement regarding electric circuits. The Turkish Online Journal of Educational Technology, 6(1), 15-24.

Bilal, E. \& Erol, M. (2009). Investigating students' conceptions of some electricity concepts. Latin American Journal of Physics Education, 3(2), 193-201.

Bonham, S.W., Risley, J.S., \& Christian, W. (1999). Using physlets to teach electrostatics. The Physics Teacher, 37(5), 276-281. 
Chabay, R. \& Sherwood, B. (2006). Restructuring the introductory electricity and magnetism course. American Journal of Physics, 74(4), 329-336.

Dancy, M.H. \& Beichner, R. (2006). Impact of animation on assessment of conceptual understanding in Physics. Physical Review Special Topics - Physics Education Research, 2(1), 1-7.

Finkelstein, N.D., Adams, W.K., Keller, C.J., Kohl, P.B., Perkins, K.K., Podolefsky, N.S., Reid, S. \& LeMaster, R. (2005). When learning about the real world is better done virtually: A study of substituting computer simulations for laboratory equipment. Physical Review Special Topics - Physics Education Research, 1(1), 1-8.

Fraser, D.M., Pillay, R., Tjatindi, L. \& Case, J.M. (2007). Enhancing the learning of fluid mechanics using computer simulations. Journal of Engineering Education, 96(4), 381388.

Gönen, S., Kocakaya, S. \& İnan, C. (2006). The effect of the computer assisted teaching and $7 \mathrm{E}$ model of the constructivist learning methods on the achievements and attitudes of high school students. The Turkish Online Journal of Educational Technology, 5(4), 8288 .

Hake, R.R. (1998). Interactive engagement vs. traditional methods: A six -thousand-student data of mechanics test data for introductory courses. American Journal of Physics, 66(1), 64-74.

Hargunani, S.P. (2010). Teaching of Faraday's and Lenz's theory of electromagnetic induction using java based Faraday's lab simulations. Latin American Journal of Physics Education, 4(3), 520-522.

Holec, S., Spodniaková Pfefferová, M. \& Raganová, J. (2004). Computer simulations in mechanics at the secondary school. Informatics in Education, 3(2), 229-238.

Keller, C.J., Finkelstein, N.D., Perkins, K.K. \& Pollock, S.J. (2007). Assessing the effectiveness of a computer simulation in introductory undergraduate environments. 2006 Physics Education Research Conference, AIP Conference Proceedings, 883, 121 124.

Kocakaya, S. \& Gonen, S. (2010). The effects of computer-assisted instruction designed according to $7 \mathrm{e}$ model of constructivist learning on physics student teachers' achievement, concept learning, self-efficacy perceptions and attitudes. The Turkish Online Journal of Distance Education, 11(3), 206-224.

Maloney, D.P., O'Kuma, T.L., Hieggelke, C.J. \& Heuvelen, A.V. (2001). Surveying students' conceptual knowledge of electricity and magnetism. American Journal of Physics, 69(S1), S12.

McBridge, D.L., Zollaman, D. \& Rebello N.S. (2010). Method for analyzing students' utilization of prior physics learning in new contexts. Physical Review Special Topics Physics Education Research, 6(2), 1-10.

McDermott, L.C. (2001). Oersted medal lecture 2001: "physics education research-the key to student learning”. American Journal of Physics, 69(11), 1127-1137.

Meltzer, D. (2005). Relation between students' problem - solving - performance and representational format. American Journal of Physics, 73(5), 463-478.

Meltzer, D.E. \& Manivannan, K. (2002). Transforming the lecture-hall environment: The fully interactive physics lecture. American Journal of Physics, 70(6), 639-654. 
Monaghan, J.M. (1998). Use of a computer simulation to develop mental simulations for understanding relative motion concepts. International Journal of Science Education, 21(9), 921- 944.

Perkins, K., Adams, M., Dubson, M., Finkelstein, N., Reid, S., Wieman, C. \& LeMaster, R. (2006). PhET: Interactive simulations for teaching and learning. The Physics Teacher, 44(1), 18-23.

Pollock, S.J. (2009). Longitudinal study of student conceptual understanding in electricity and magnetism. Physical Review Special Topics - Physics Education Research, 5(2), 1-8.

Saarelainen, M. \& Hirvonen, P.E. (2009). Designing a teaching sequence for electrostatics at undergraduate level by using educational reconstruction. Latin American Journal of Physics Education, 3(3), 518-526.

Serin, O. (2011). The effects of the computer-based instruction on the achievement and problem solving skills of the science and technology students. The Turkish Online Journal of Educational Technology, 10(1), 183-201.

Tao, P.K. \& Gunstone, R.F. (1999). The process of conceptual change in force and motion during computer-supported physics instruction. Journal of Research in Science Teaching, 36(7), 859-882.

Ubiña, T.D. \& Patricio, O.M. (2007). Development of validated computer simulated projectile motion experiments (C-SPEX) for teaching kinematics. MMSU Science and Technology Journal, 1(1), 103-110.

Yeşilyurt, M. (2011). Meta analysis of the computer assisted studies in physics: A sample of Turkey. Energy Education Science and Technology Part B: Social and Educational Studies, 3(2): 173-182. 